\title{
Article \\ Examining the Impact of Squaric Acid as a Crosslinking Agent on the Properties of Chitosan-Based Films
}

\author{
Ewa Olewnik-Kruszkowska ${ }^{1, *(\mathbb{D})}$, Magdalena Gierszewska ${ }^{1, *(\mathbb{C})}$, Sylwia Grabska-Zielińska ${ }^{1}$, \\ Joanna Skopińska-Wiśniewska ${ }^{2}$ and Ewelina Jakubowska ${ }^{1}$ (D) \\ 1 Department of Physical Chemistry and Physicochemistry of Polymers, Faculty of Chemistry, \\ Nicolaus Copernicus University in Toruń, Gagarina 7, 87-100 Toruń, Poland; sylwia.gz@umk.pl (S.G.-Z.); \\ ewelina@doktorant.umk.pl (E.J.) \\ 2 Department of Chemistry of Biomaterials and Cosmetics, Faculty of Chemistry, \\ Nicolaus Copernicus University in Toruń, Gagarina 7, 87-100 Toruń, Poland; joanna@umk.pl \\ * Correspondence: olewnik@umk.pl (E.O.-K.); mgd@umk.pl (M.G.); \\ Tel.: +48-56-611-2210 (E.O.-K.); +48-56-611-4524 (M.G.)
}

check for updates

Citation: Olewnik-Kruszkowska, E.; Gierszewska, M.; Grabska-Zielińska,

S.; Skopińska-Wiśniewska, J.;

Jakubowska, E. Examining the Impact of Squaric Acid as a Crosslinking

Agent on the Properties of

Chitosan-Based Films. Int. J. Mol. Sci.

2021, 22, 3329. https://doi.org/

$10.3390 /$ ijms22073329

Academic Editor: Iolanda Francolini

Received: 24 February 2021

Accepted: 20 March 2021

Published: 24 March 2021

Publisher's Note: MDPI stays neutral with regard to jurisdictional claims in published maps and institutional affiliations.

Copyright: (C) 2021 by the authors. Licensee MDPI, Basel, Switzerland. This article is an open access article distributed under the terms and conditions of the Creative Commons Attribution (CC BY) license (https:/ / creativecommons.org/licenses/by/ $4.0 /)$.

\begin{abstract}
Hydrogels based on chitosan are very versatile materials which can be used for tissue engineering as well as in controlled drug delivery systems. One of the methods for obtaining a chitosan-based hydrogel is crosslinking by applying different components. The objective of the present study was to obtain a series of new crosslinked chitosan-based films by means of solvent casting method. Squaric acid-3,4-dihydroxy-3-cyclobutene-1,2-dione-was used as a safe crosslinking agent. The effect of the squaric acid on the structural, mechanical, thermal, and swelling properties of the formed films was determined. It was established that the addition of the squaric acid significantly improved Young's modulus, tensile strength, and thermal stability of the obtained materials. Moreover, it should be stressed that the samples consisting of chitosan and squaric acid were characterized by a higher swelling than pure chitosan. The detailed characterization proved that squaric acid could be used as a new effective crosslinking agent.
\end{abstract}

Keywords: chitosan; squaric acid; crosslinking; swelling; mechanical properties

\section{Introduction}

Chitosan is a natural polymer consisting of randomly distributed $\beta-(1-4)$-linked Dglucosamine and N-acetyl-D-glucosamine units. The increasing interest in this polymer is related to its low toxicity and biocompatibility, as well as its susceptibility to enzymatic degradation. Moreover, contrary to a synthetic polymer, chitosan does not present immunogenicity. For this reason, chitosan is one of the polymers used for the formation of hydrogels, which have to meet a significant number of requirements set forth by the medical, pharmaceutical, and food packaging sectors. It is well known that hydrogels have to be characterized by improved mechanical properties, and that they have to ensure effective stability in different $\mathrm{pH}$ levels simultaneously, exhibiting $\mathrm{pH}$-responsive swelling. For this reason, in an aim to achieve all of the properties mentioned above, the process of crosslinking started to be viewed as a viable solution. It is well known that the crosslinking of chitosan significantly affects the swelling and sorption potentials, as well as its transport and mechanical properties.

In order to obtain crosslinked chitosan, different types of methods and agents can be applied. For this purpose, primarily chemical and physical modifications are used. In the case of physical methods, where ionic interactions between the polymer chains occur, among different inorganic ionic compounds, calcium chloride and pentasodium tripolyphosphate are applied as crosslinking agents [1-3].

In the case of chemically crosslinked materials, the most popular crosslinking molecules include: glutaraldehyde [4,5], formaldehyde [6], boric acid [7], epichlorohydrin [8], and ethylene glycol diglycidyl ether [9]. These crosslinking agents, however, are characterized by toxic 
properties in their unreacted forms. For this reason, although a high degree of crosslinking can efficiently be achieved in their case, further application is significantly limited. A solution to the toxicity dilemma can be attained by application of a new crosslinking agent; for example, one of the aldehyde-functionalized compounds such as cellulose [10], $\beta$-cyclodextrin [11], starch [12], dialdehyde starch [13], or dextran [14]. Moreover, instead of toxic crosslinking agents, enzymatic crosslinking by means of transglutaminase can be applied [14-17]. Despite the considerable number of components used as crosslinking agents, new reactants are still being sought and tested. One of the components which can be used as a chitosan crosslinking agent is 3,4-dihydroxy-3-cyclobutene-1,2-dione, known as squaric acid $\left(\mathrm{H}_{2} \mathrm{SQ}\right)$. It should be stressed that squaric acid is a cyclic organic acid without any carboxyl groups (Figure 1). Its name refers to the square shape of the molecule created by four interconnected carbon atoms. The reactivity of squaric acid with amine groups was presented in the work of Wurm and Klock [18]. The formulation of magnetic nanoparticles coated with chitosan and crosslinked with squaric acid was described by Ziegler-Borowska et al. [19]. Moreover, squaric acid was described by Skopińska-Wiśniewska as an effective crosslinking agent of the collagen/elastin hydrogels [20]. It is worth noting that Skopińska-Wiśniewska et al. [20] analyzed also the biological properties of collagen/elastin materials crosslinked by $\mathrm{H}_{2} \mathrm{SQ}$. The in vitro test performed with the 3T3 cell line revealed that the addition of the crosslinking agent resulted in only a slight, not statistically significant, decrease in the cellular response. Based on these findings, it can be suggested that $\mathrm{H}_{2} \mathrm{SQ}$ can be regarded as a safe compound in comparison to other, toxic crosslinking agents indicated above.

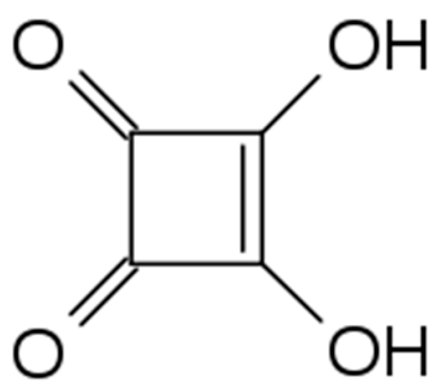

Figure 1. Chemical structure of squaric acid $\left(\mathrm{H}_{2} \mathrm{SQ}\right)$.

Obtained results allowed us to establish that squaric acid readily reacts with both of the protein materials mentioned above. To the best of our knowledge there is no indication of any paper reporting on the effect of squaric acid as the crosslinking agent of chitosan-based films.

For this reason, in the present work, the influence the introduction of squaric acid into the chitosan matrix has on its properties has been examined.

In order to establish the extent of changes occurring in the structure as well as in the morphology after an addition of squaric acid, Fourier transform infrared spectroscopy (FTIR) and atomic force microscopy (AFM) were applied. The thermal stability of chitosan before and after crosslinking was analyzed. Moreover, mechanical properties, as well as the swelling of the obtained materials in mediums characterized by different $\mathrm{pH}$ levels, were determined. Chitosan crosslinked by means of squaric acid presented significantly improved mechanical and swelling properties. The obtained results clearly show that squaric acid belongs to the group of effective crosslinking agents.

\section{Results and Discussion}

\subsection{Fourier Transform Infrared Spectroscopy}

To confirm the internal chemical structure of the chitosan-based films and to prove the successful chitosan crosslinking with 3,4-dihydroxy-3-cyclobutene-1,2-dione (squaric acid, $\mathrm{H}_{2} \mathrm{SQ}$ ), the FTIR spectrum of the $\mathrm{H}_{2} \mathrm{SQ}$ in $\mathrm{KBr}$-disc form, along with the Fourier transform infrared-Attenuated Total Reflectance (FTIR-ATR) spectra of pristine chitosan, and $\mathrm{H}_{2} \mathrm{SQ}$-modified chitosan films were compared (Figures 2 and 3 ). 


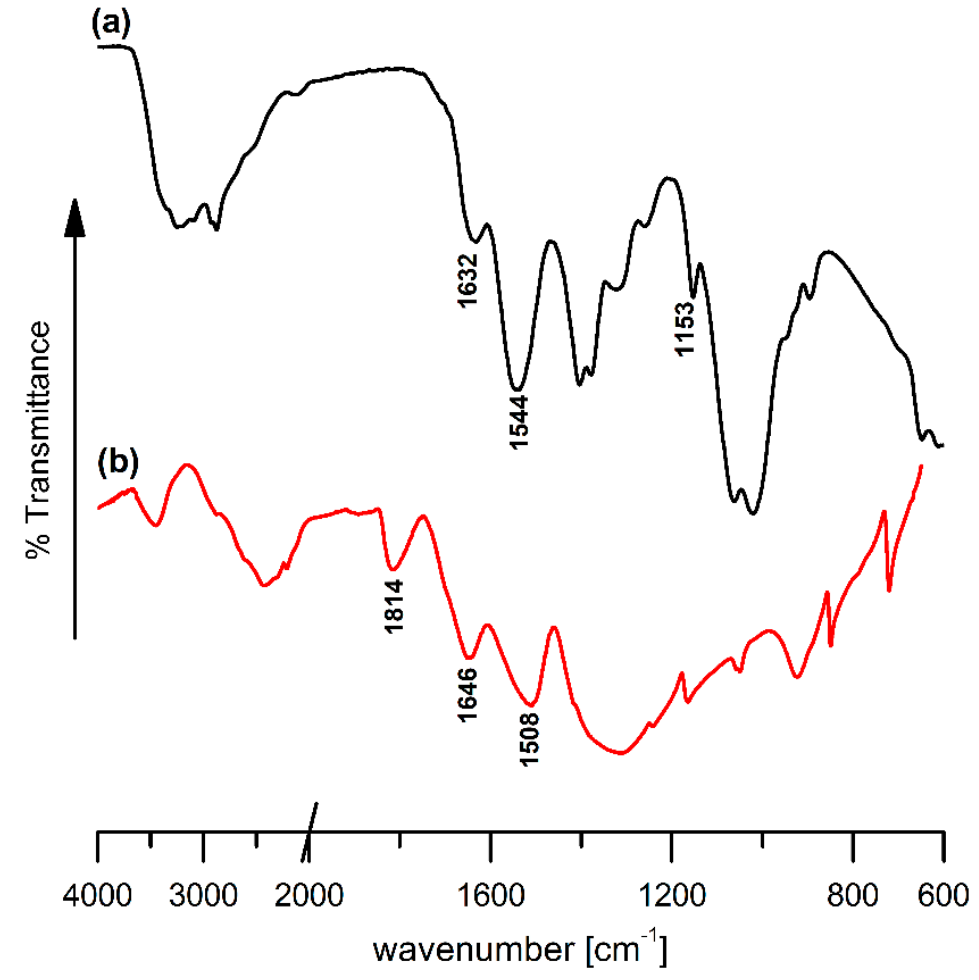

Figure 2. (a) Fourier transform infrared-Attenuated Total Reflectance (FTIR-ATR) spectrum of chitosan (Ch) and (b) Fourier transform infrared (FTIR) spectrum of squaric acid $\left(\mathrm{H}_{2} \mathrm{SQ}\right)$.
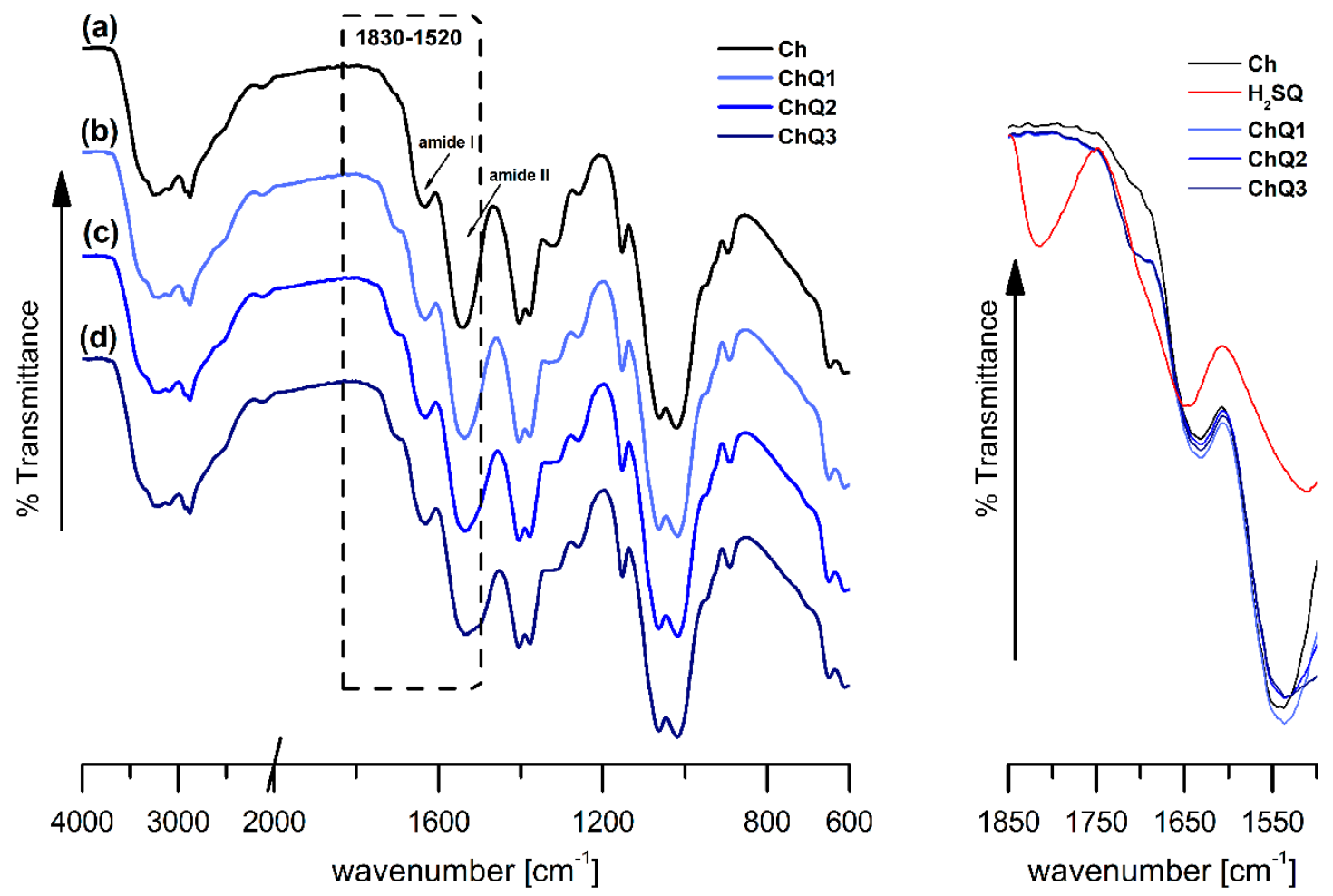

Figure 3. FTIR-ATR spectra of (a) chitosan (Ch) and squaric acid-crosslinked chitosan, (b) ChQ1, (c) ChQ2, and (d) ChQ3 (left: stacked spectra, right: overlapped spectra).

The spectrum of neat chitosan film (Figure 2a) is consistent with the spectra described earlier in the literature [21-24]. Among numerous vibrational bands typical of chitosan 
and indicated previously [21-24], the most characteristic include: $v(\mathrm{O}-\mathrm{H})$ and $v(\mathrm{~N}-\mathrm{H})$ stretching vibrations (maximum at $\left.3251 \mathrm{~cm}^{-1}\right), v(\mathrm{C}=\mathrm{O})$ stretching in the amide group (amide I vibration, $\left.1632 \mathrm{~cm}^{-1}\right), \delta(\mathrm{N}-\mathrm{H})$ bending in the amide group (amide II vibration, $\left.1544 \mathrm{~cm}^{-1}\right)$, antisymmetric stretching of the $\mathrm{C}-\mathrm{O}-\mathrm{C}$ bridge $\left(1153 \mathrm{~cm}^{-1}\right)$, and skeletal vibrations involving the $\mathrm{C}-\mathrm{O}$ stretching $\left(1062\right.$ and $\left.1021 \mathrm{~cm}^{-1}\right)$.

The infrared spectrum of the squaric acid (Figure 2b) shows a strong broad band at $1508 \mathrm{~cm}^{-1}$ representing overlapped stretching $v(C=C)$ and $v(C=O)$ vibrations $[25,26]$. The presence of a $\mathrm{C}=\mathrm{O}$ bond can be also confirmed through the asymmetric stretching vibration $v_{\mathrm{as}}(\mathrm{C}=\mathrm{O})$ at $1814 \mathrm{~cm}^{-1}$. A very intense band at $1314 \mathrm{~cm}^{-1}$ represents the stretching $v(\mathrm{C}-\mathrm{C})$ vibrations. Other, less intense bands correspond to [25-27]: $v(C=C)$ stretching $\left(1646 \mathrm{~cm}^{-1}\right)$, $v(\mathrm{C}-\mathrm{C})$ stretching $\left(1166,1049,924\right.$, and $\left.850 \mathrm{~cm}^{-1}\right)$, and ring breathing $(\mathrm{C}-\mathrm{C}$ in-phase (symmetric motion) ring stretching vibrations, $721 \mathrm{~cm}^{-1}$ ).

A comparison of FTIR spectra of the pristine chitosan film (Ch), squaric acid, and $\mathrm{H}_{2} \mathrm{SQ}$ modified chitosan films (ChQ1, ChQ2, and ChQ3, see Materials and Methods) (Figures 2 and 3) revealed differences in the regions corresponding to $\mathrm{C}=\mathrm{O}$ and $-\mathrm{NH}_{2}$ vibrations (1830-1520 $\mathrm{cm}^{-1}$ region). After adding the crosslinking agent, absorption bands related to the $\mathrm{N}-\mathrm{H}$ bending in the amide group (amide II vibration) changed in their positions, while $\mathrm{C}=\mathrm{O}$ stretching in the amide group (amide I vibration) was almost unaffected (Table 1). The peak at $1544 \mathrm{~cm}^{-1}$ shifted to ca. $1536 \mathrm{~cm}^{-1}$ and in the region of about $1720-1560 \mathrm{~cm}^{-1}$ a broad band with a maximum at approximately $1631 \mathrm{~cm}^{-1}$ and a small shoulder at ca. $1700 \mathrm{~cm}^{-1}$ was observed.

Table 1. The position of characteristic bands $\left[\mathrm{cm}^{-1}\right]$ in the FTIR spectra of $\mathrm{H}_{2} \mathrm{SQ}$ powder, and Chand squaric acid-modified chitosan films.

\begin{tabular}{ccccc}
\hline Sample & C=O & C=C & Amide I & Amide II \\
\hline $\mathrm{H}_{2} \mathrm{SQ}$ & 1814 & 1645 & -2 & -2 \\
Ch & -2 & -2 & 1632 & 1544 \\
ChQ1 & -2 & $\sim 1700^{1}$ & 1631 & $1537^{3}$ \\
ChQ2 & -2 & $\sim 1691^{1}$ & 1631 & $1536^{3}$ \\
ChQ3 & -2 & $\sim 1700^{1}$ & 1631 & $1536^{3}$ \\
\hline
\end{tabular}

${ }^{1}$ visible as a small shoulder on the amide I vibration band. ${ }^{2}$ not detected. ${ }^{3}$ amide II and $\mathrm{C}=\mathrm{N}$.

According to our previous findings [2,28], and based on the knowledge that Schiff bases absorb in the range $1620-1660 \mathrm{~cm}^{-1}$ [29], it is reasonable to assume that the intense band at ca. $1631 \mathrm{~cm}^{-1}$ is a result of overlapping of the amide I vibration of chitosan and the $\mathrm{C}=\mathrm{N}$ stretching of a Schiff base. As can be seen, the intensity of this band increases slightly after squaric acid crosslinking (Figure 3 (right)), in comparison to the neat chitosan film spectrum. Similar observations have been made by Ziegler-Borowska et al. [30] in relation to biopolymeric magnetic nanoparticles crosslinked with glutaraldehyde and squaric acid, who also indicated that the increase in the band intensity was the result of the formation of new $\mathrm{C}=\mathrm{N}$ bonds. Moreover, Souza et al. [31] also suggested, in the case of $\mathrm{H}_{2} \mathrm{SQ}$-modified chitosan, that a new band at $1536 \mathrm{~cm}^{-1}$ should be assigned to the $v(\mathrm{C}=\mathrm{N})$. As indicated by Ziegler-Borowska et al. [30], in the spectra of chitosan/squaric acid $/ \mathrm{Fe}_{3} \mathrm{O}_{4}$ systems a band at $1438 \mathrm{~cm}^{-1}$ was noted and assigned to the -OH (-O-) bending vibrations from squaric moiety. The band was not noted in the ChQ spectra (Figure $3 b-d$, left) as it corresponded to a similar wavelength as the $\mathrm{C}-\mathrm{H}$ vibration at $\mathrm{CH}_{2}$ groups in the pyranose ring of chitosan (Figure 3a, left).

The changes discussed above indicate that the formation of chemical crosslinks between chitosan and squaric acid, schematically shown in Figure 4, has indeed taken place. 


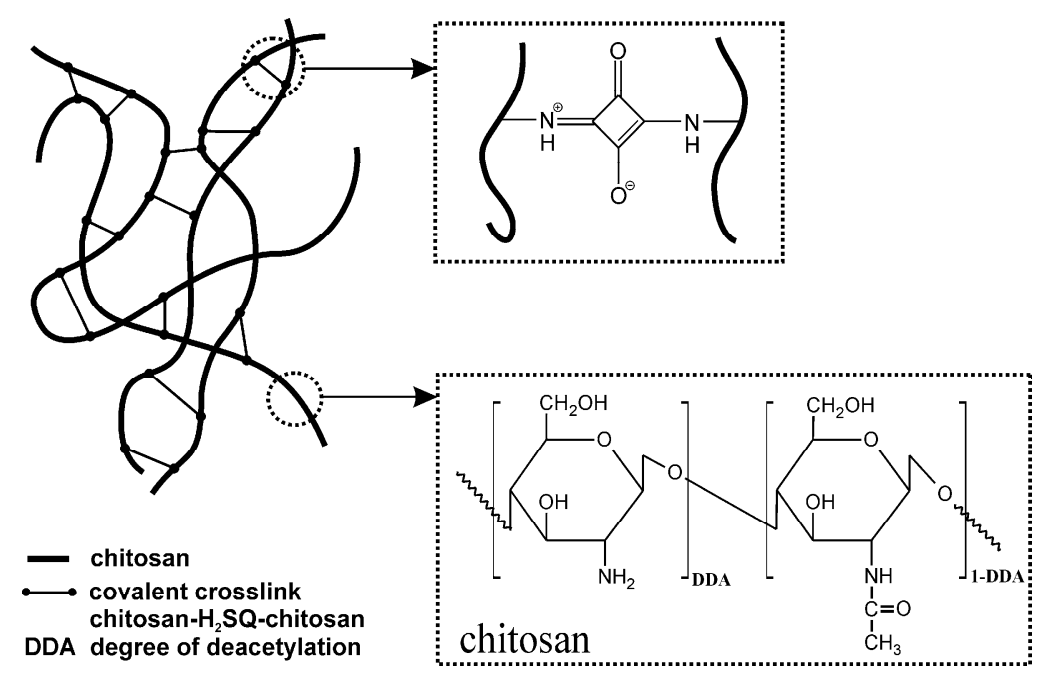

Figure 4. Schematic chemical structure of chitosan crosslinked with squaric acid.

Analysis of the crosslinked structure presented in Figure 4 suggests the presence of $\mathrm{C}=\mathrm{O}$ functional groups in the $\mathrm{ChQ}$ structure. It can also be noticed, however, that in the spectra of ChQ the band characteristic of squaric acid at $1814 \mathrm{~cm}^{-1}\left(v_{\mathrm{as}}(\mathrm{C}=\mathrm{O})\right)$ is missing. The lack of this band was also observed in the $\mathrm{H}_{2} \mathrm{SQ}$-crosslinked chitosan spectrum presented by Souza et al. [31], despite the fact that this sample was obtained with an excess of the crosslinker (polymer:crosslinker weight ratio $=1: 2$ ). It is worth noting that the amount of the crosslinking agent (squaric acid) in ChQ1-ChQ3 films is relatively small when compared to the mass of the crosslinked polymer (up to $3 \mathrm{wt} . \%$ of chitosan), thus changes observed in FTIR spectra are also relatively small and bands' intensities are dominated by the vibrations of functional groups present in chitosan. Based on the known value of the chitosan degree of deacetylation, and the relative amounts of chitosan and the crosslinker, assuming that one mole of the crosslinker reacts with two moles of the $-\mathrm{NH}_{2}$ functional groups (Figure 4), the theoretical degree of chitosan crosslinking with squaric acid was found to equal $4.19,8.38$, and $12.57 \%$ in the case of the ChQ1, ChQ2, and ChQ3 samples, respectively.

\subsection{Swelling}

One of the most important features of neat chitosan and chitosan-based materials is their swelling behavior in contact with different external media. It is a crucial property in terms of evaluating possible biomedical and pharmaceutical applications, especially in controlled drug delivery systems, and in the food packaging industry, as it determines the diffusion of solute, wettability, and mechanical properties.

According to the Flory-Rehner theory, in general, a crosslinked polymer gel immersed in an external media and in the process of reaching an equilibrium with its surroundings, is subject only to two opposing forces, i.e. the thermodynamic force of mixing and the retractive force of the polymer chains [32,33]. These forces become equal at equilibrium state, thus the physical situation can be described by the following Gibbs free energy formula:

$$
\Delta G_{\text {total }}=\Delta G_{\text {elastic }}+\Delta G_{\text {mixing }}
$$

where $\Delta G_{\text {elastic }}$ represents the elastic retractive forces inside the material and correlates with the degree of crosslinking, while $\Delta G_{\text {mixing }}$ represents the mixing of the solute molecules with the polymer chains and can be regarded as an affinity between the polymer and the components of the external fluid (polymer-solvent interaction).

Theoretical considerations about equilibrium swelling become more complex for those polymeric systems in which ionic moieties are present. Due to the ionic nature of the 
polymer network, additional contribution $\left(\Delta G_{\text {ionic }}\right)$ must be taken into account in the total change in Gibbs free energy [32,33]:

$$
\Delta G_{\text {total }}=\Delta G_{\text {elastic }}+\Delta G_{\text {mixing }}+\Delta G_{\text {ionic }}
$$

As it was already proved by other researchers [34,35], polymeric materials formed from weak polyelectrolytes, like chitosan, undergo changes in swelling in response to changes in $\mathrm{pH}$ and ionic strength. In many cases, in evaluations of the effect of different $\mathrm{pH}$ levels on equilibrium swelling value, the ionic composition of the buffer is neglected. In Figure 5 the equilibrium swelling values of $\mathrm{Ch}$ and $\mathrm{ChQ}$ films in pure water and different buffered solutions of constant ionic strength are compared.

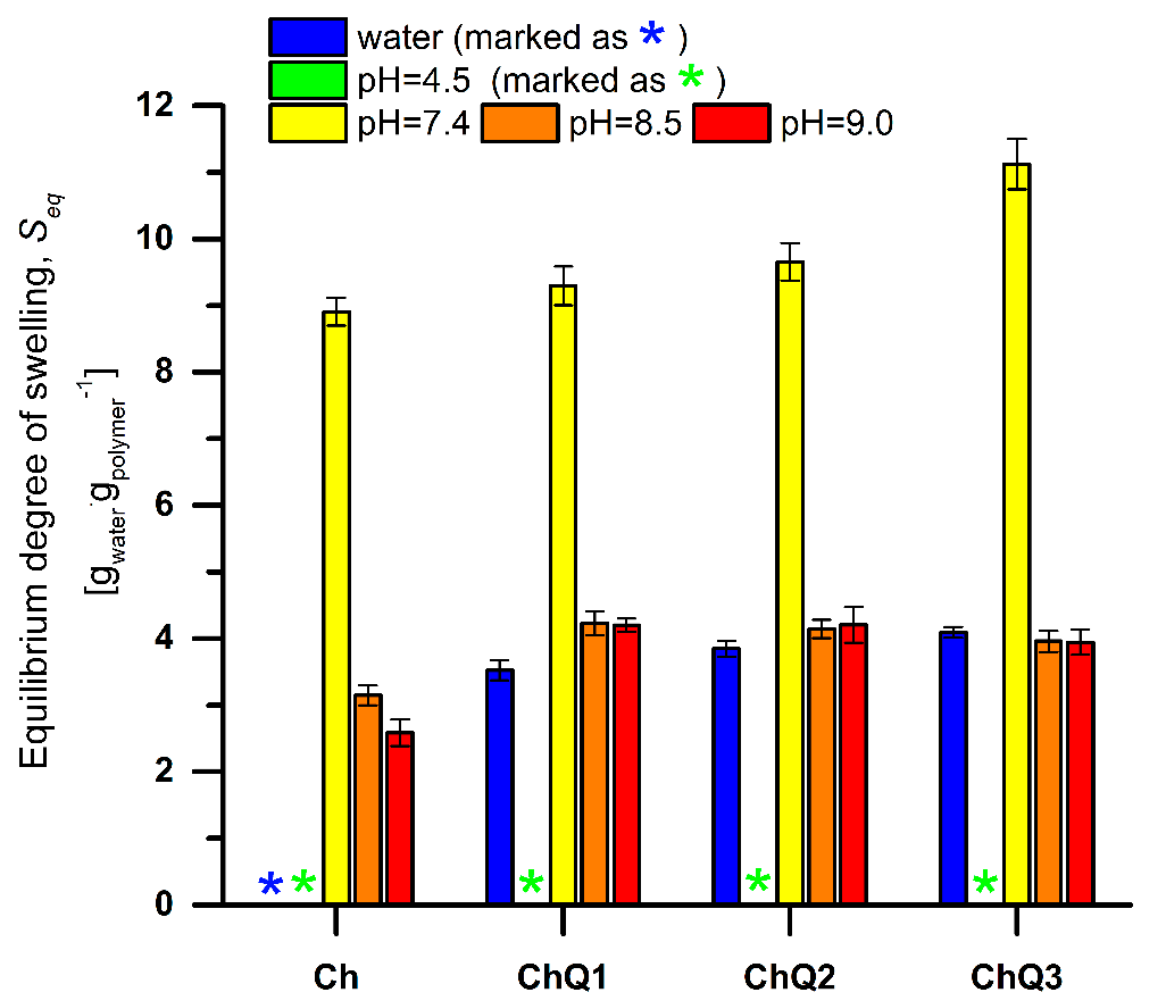

Figure 5. Equilibrium swelling degree of non-modified and squaric acid-crosslinked chitosan films in water and different buffered solutions.

The swelling capacity of all $\mathrm{Ch}$ and covalently crosslinked chitosan (ChQ) films is highly dependent on the $\mathrm{pH}$ of the swelling medium. As can be seen, both non-crosslinked and crosslinked chitosan films undergo dissolution in an acidic $(\mathrm{pH}=4.5)$ media. The $S_{e q}$ value decreases with increasing $\mathrm{pH}$; however, differences between $\mathrm{pH} 8.5$ and 9.0 solutions, for ChQ films, are within the measurement error.

The disintegration of all of the tested films occurring in $\mathrm{pH} 4.5$ results from the chemical nature of chitosan and the relatively small degree of crosslinking (the highest: $12.57 \%$ degree of crosslinking for ChQ3). Chitosan belongs to the weak polybases and is characterized by $\mathrm{pKa} \approx 6.5$ [36]. At $\mathrm{pH}<\mathrm{pKa}$ the $-\mathrm{NH}_{2}$ functional groups of $\mathrm{Ch}$ are almost completely ionized, forming $-\mathrm{NH}_{3}{ }^{+}$(degree of chitosan ionization $99 \%$, Figure 6), increasing simultaneously with the osmotic pressure inside the polymeric network. Repulsion of the equally charged $-\mathrm{NH}_{3}{ }^{+}$functional groups also enhances the relaxation of macromolecular chains. As a result, in these $\mathrm{pH}$ conditions, the water uptake is so high that it leads to mechanical disintegration. Comparison between $\mathrm{Ch}$ and $\mathrm{ChQ}$ films indicates that the number of formed chemical crosslinks, as well as their strength, and the $12.57 \%$ degree of crosslinking, are not high enough to prevent breakdown. 


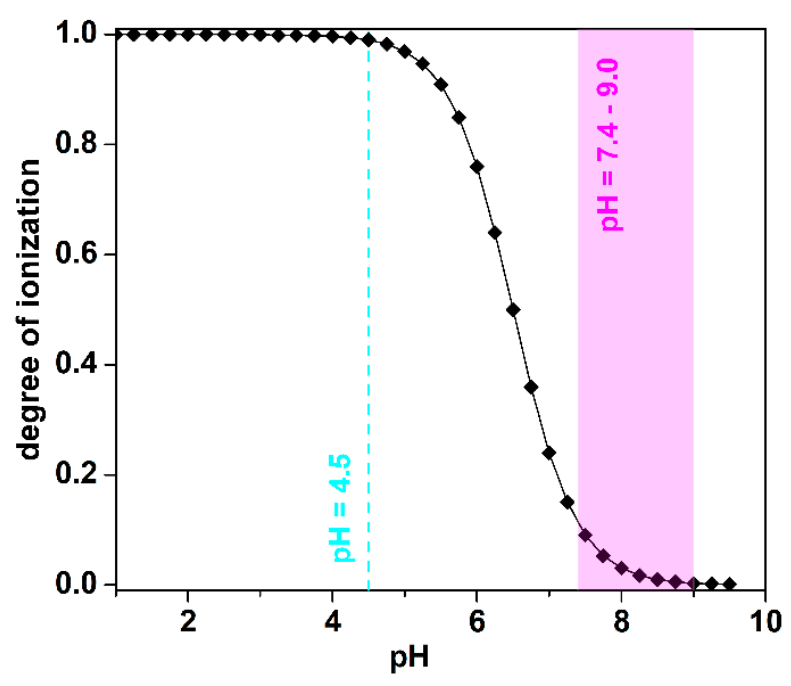

Figure 6. Degree of ionization of chitosan vs. $\mathrm{pH}$.

Data presented in Figure 5 confirm that all, non-crosslinked and crosslinked, chitosan films swell, do not disintegrate, and reach equilibrium swelling state in buffered solutions of $\mathrm{pH}$ higher than 7.4. The differences in swelling capacity with an increasing $\mathrm{pH}$ correspond to the chemical nature of the polymeric network and confirm that one of the major factors contributing to the swelling of chitosan-based materials is the state of ionizable functional groups present within the network. At $\mathrm{pH}$ higher than 7.4 only a few amino functional groups are ionized (degree of chitosan ionization $<10 \%$, Figure 6), thus repulsive forces are lower than those in the polymeric films swelled at $\mathrm{pH}$ 4.5. As a result of an increasing pH, a decrease in $S_{e q}$ is observed and the films' swelling is mainly controlled by hydrophilic groups of all components.

The observed differences in swelling of the squaric acid-crosslinked chitosan films are also related to the number and nature of interactions between the chitosan chains and the crosslinking agents. Generally, a lower crosslinking density results in a higher swelling capacity [33,35]. In turn, a higher crosslinking density causes a simultaneous reduction in the degree of swelling values and the $\mathrm{pH}$-sensitive swelling, while improving the stability of the network [37,38]. In the crosslinked networks, however, the hydrophilic/hydrophobic balance and tacticity should also be taken into account [39]. Analysis of the $S_{e q}$ values for the Ch, ChQ1, ChQ2, and ChQ3 (Figure 5) films indicates that covalent crosslinking with squaric acid slightly increases the swelling of the $\mathrm{Ch}$ materials, even if the degree of chitosan crosslinking increases. As confirmed during the FTIR analysis, the ChQ1, ChQ2, and ChQ3 films differ in the number of covalent crosslinks, with the highest count recorded in the case of the ChQ3 material. In general, the presence of chemical crosslinks reduces the chain mobility and also reduces swelling. Higher $S_{e q}$ values of the $\mathrm{H}_{2} \mathrm{SQ}$-crosslinked chitosan networks at $\mathrm{pH}>7.4$ (in comparison to neat $\mathrm{Ch}$ ) indicate that the hydrophobic/hydrophilic balance plays a crucial role in swelling properties. Neat chitosan films are regarded as hydrophilic due to the presence of amine $\left(-\mathrm{NH}_{2}\right)$, hydroxyl $(-\mathrm{OH})$, and ether $(\mathrm{C}-\mathrm{O}-\mathrm{C})$ polar groups, that can be involved in interactions with water through the hydrogen bonds. Even if the crosslinking process reduces the number of free amino groups, the - $\mathrm{NH}-$ functionals are still present (Figure 4). Moreover, the new functional groups $\mathrm{C}=\mathrm{O}$ and $\mathrm{C}-\mathrm{O}-$ appear. Shikata and Okuzono [40], who determined the hydration numbers of compounds containing a carbonyl group as equal to ca. 0 at $25{ }^{\circ} \mathrm{C}$, classified these compounds as the newly defined "hydroneutral" substances. Such hydroneutral compounds display very weak interaction with water molecules due to their unique characteristic of zero hydration number. The $\mathrm{C}=\mathrm{O}$ functional groups, present in a crosslinked chitosan network, can act as hydrogen bond acceptors, enhancing the interactions between the polymeric network and water, and finally enhancing swelling ability. A similar effect on the swelling capacity, resulting from the presence of the $\mathrm{C}=\mathrm{O}$ functionals, was observed earlier by Ewing et. al [41], in the case 
of the $\mathrm{CO}_{2}$ sorption by different polymeric materials (unsaturated polyketones). These authors concluded that the concentration of the Lewis basic groups in polymers increased the overall polymer swelling. In summary, both differences in crosslinking density and in hydrophilicity of the network affect the equilibrium swelling value. Crosslinking with $\mathrm{H}_{2} \mathrm{SQ}$ decreases swelling capacity, while the presence of the $\mathrm{C}=\mathrm{O}$ functionals derived from the crosslinker enhances this property. As for ChQ films swelled at $\mathrm{pH}$ 7.4, the equilibrium swelling value increases with an increasing crosslinker amount, which leads to the conclusion that the effect of the crosslinker-water interactions prevails over the effect of a higher crosslinking density.

A similar phenomenon is noted in the case of $\mathrm{H}_{2} \mathrm{SQ}$-crosslinked chitosan samples swelled in water (Figure 5). The highest value of equilibrium swelling degree $\left(4.09 \pm 0.08 \mathrm{~g}_{\text {water }} \cdot \mathrm{g}_{\text {polymer }}{ }^{-1}\right)$ is observed in relation to the ChQ3 sample, representing the highest degree of crosslinking value. It should also be emphasized that, contrary to the pristine chitosan film, all crosslinked chitosan samples do not disintegrate in $\mathrm{H}_{2} \mathrm{O}$ media. This clearly indicates that the crosslinking process, and newly covalent crosslinks formed within the chitosan material, improve the chitosan film stability. Comparison of swelling data for neat and crosslinked chitosan in water ( $\mathrm{pH}=7$, Figure 5, blue bar) and in buffered solution of $\mathrm{pH}=7.4$ (Figure 5, yellow bar) confirms the conclusion that ionic strength and the presence of ionic species in the solution also affect swelling of polyelectrolyte-based materials.

\subsection{Changes in Surface Morphology Determined Using AFM Technique}

The 2D and 3D surface morphology images of films obtained from pure chitosan and chitosan crosslinked by adding 1, 2, and 3 wt.\% of squaric acid are presented in Figure 7. The corresponding roughness parameters are shown in Table 2, where the $R_{q}$ and $R_{a}$ values are presented. $R_{q}$ (root mean square roughness) represents the standard deviation of the distribution of surface heights. $R_{a}$ (arithmetic average height parameter) is defined as the average absolute deviation of the roughness irregularities from the mean line over one sampling length [42]. It is the most universally recognized roughness parameter estimate used in quality control.
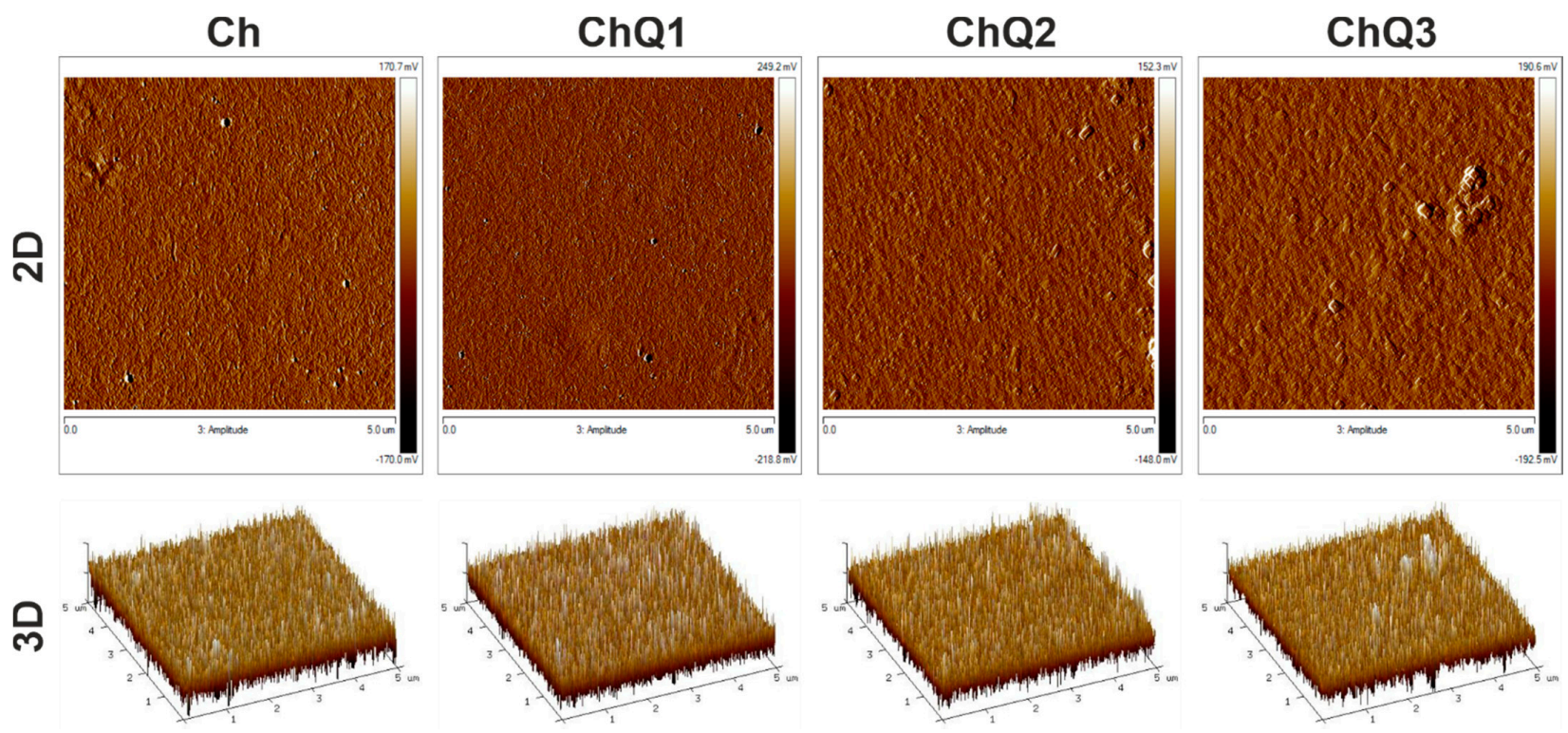

Figure 7. 2D and 3D atomic force microscopy (AFM) images of the surface topography of Ch and ChQ films. 
Table 2. Values of roughness root mean square roughness $\left(R_{\mathrm{q}}\right)$ and roughness average $\left(\mathrm{R}_{\mathrm{a}}\right)$ parameters and thermal stability of studied materials.

\begin{tabular}{ccccc}
\hline Sample & $\mathbf{R}_{\mathbf{q}}[\mathbf{n m}]$ & $\mathbf{R}_{\mathbf{a}}[\mathbf{n m}]$ & $\mathbf{T}_{\mathbf{5} \%}\left[{ }^{\circ} \mathbf{C}\right]$ & $\mathbf{T}_{\mathbf{1 0} \%}\left[{ }^{\circ} \mathbf{C}\right]$ \\
\hline Ch & $2.30 \pm 0.02$ & $1.89 \pm 0.03$ & $104.9 \pm 0.2$ & $145.7 \pm 0.6$ \\
ChQ1 & $2.68 \pm 0.04$ & $2.19 \pm 0.10$ & $105.4 \pm 0.2$ & $147.2 \pm 0.3$ \\
ChQ2 & $2.99 \pm 0.04$ & $2.51 \pm 0.11$ & $106.2 \pm 0.4$ & $147.9 \pm 0.2$ \\
ChQ3 & $3.67 \pm 0.05$ & $2.95 \pm 0.13$ & $115.8 \pm 0.5$ & $158.6 \pm 0.9$ \\
\hline
\end{tabular}

To determine the impact of squaric acid addition on chitosan films, pure chitosan film was used as a control sample. In particular, the influence of the amount of squaric acid on surface parameters was tested. As it can be seen (Figure 7), the AFM images do not reveal differences in the surface properties of films in the case of a pure chitosan film compared to crosslinked films. Two-dimensional images indicate the homogeneity of each tested sample consisting of chitosan and squaric acid. An imperfection was observed in the 2D image of chitosan with the $3 \mathrm{wt} . \%$ addition of squaric acid (Figure 7: ChQ3). This can either result from a contamination of the sample or suggest that chitosan and squaric acid solutions are not always uniformly miscible.

The slight differences are visible in the values of roughness parameters. The surface roughness increases with an increasing content of the crosslinking agent (Table 2). This may indicate an increase in the heterogeneity of crosslinked samples in comparison to neat chitosan film. The surface roughness parameters' values, both $R_{q}$ and $R_{a}$, are highest in the case of chitosan crosslinked by $3 \mathrm{wt} . \%$ of squaric acid ( 3.67 and $2.95 \mathrm{~nm}$, respectively). The observed changes in morphology are related to the interactions between polymeric compounds (chitosan) and the crosslinking agent (squaric acid). Neat chitosan films exhibit the lowest $R_{a}$ and $R_{q}$ values which most likely occurs due to the high intrinsic chain stiffness of this polymer [43]. Addition of the crosslinker into the film-forming solution, and formation of additional covalent crosslinks between polymeric chains causes a reduction in chain mobility. Consequently, after drying, a slightly less uniform, rougher surface is observed (Table 2). A higher content of the crosslinking agent in chitosan-based films and a higher number of covalent crosslinks results in a slight increase in the values of the $\mathrm{R}_{\mathrm{q}}$ and $R_{a}$ parameters. The effect of other crosslinking agents on chitosan and its mixtures was observed earlier by other researchers. In the work of Sionkowska et al., dialdehyde starch was a modifier for chitosan and mixtures of collagen, hyaluronic acid, and chitosan [44]. After modification, the observed roughness was higher for crosslinked materials than in the case of pure chitosan, but lower for crosslinked polymeric mixtures than uncrosslinked ones [44]. In relation to chitosan and chitosan/montmorillonite materials crosslinked by glutaraldehyde, roughness parameters' values were lower after modifications [3]. In the case of chitosan films crosslinked with tannic acid, a similar correlation to the one in our research was observed [45]. Roughness parameters' values were higher for chitosan with 5 and $20 \%$ of tannic acid content, as the crosslinking agent. To the best of our knowledge, there is no information on the influence of squaric acid on polymeric films' roughness.

\subsection{Thermal Properties}

Thermogravimetric analysis is one of the techniques often used to establish the influence of different additives on the thermal stability of polymeric-based materials, a crucial feature of its further application in different areas. For this reason, the effect of squaric acid on the changes in thermal properties of the investigated materials, consisting of chitosan and squaric acid, have been analyzed. Figure 8 shows TG (thermogravimetry) and DTG (differential thermogravimetry) curves obtained in the case of unmodified chitosan and chitosan crosslinked using a different amount of squaric acid. The values of temperatures at 5 and $10 \%$ mass loss $\left(\mathrm{T}_{5 \%}, \mathrm{~T}_{10 \%}\right)$ of the chitosan-based materials were selected and presented in Table 2. 


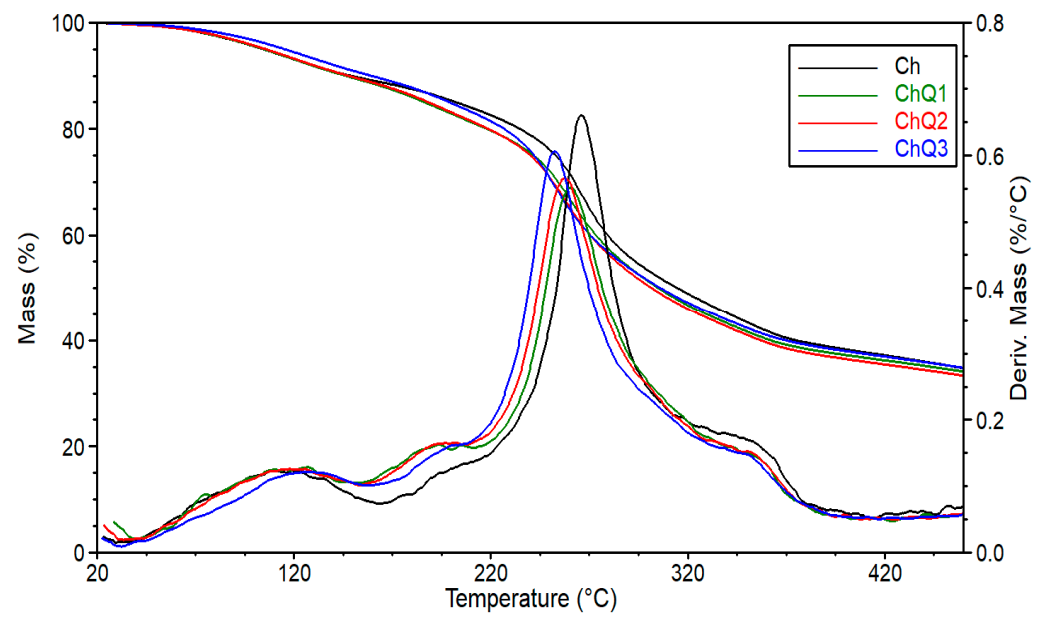

Figure 8. TG and DTG curves of unmodified (Ch) and modified chitosan (ChQ).

In the case of samples crosslinked by means of 1 and $2 \mathrm{wt} . \%$ of squaric acid no noticeable change in the values of the analyzed parameters are observed. This is consistent with the literature, where glutaraldehyde was applied as the crosslinking agent of chitosan [3]. It is well known that chitosan-based films are formed from a water solution and mass lost up to $10 \mathrm{wt} . \%$ occurring in a range between 50 and $130{ }^{\circ} \mathrm{C}$ can be mostly attributed to moisture vaporization [46]. The second stage of decomposition observed in Figure 8 $\left(140-265{ }^{\circ} \mathrm{C}\right)$ is related to the degradation of chitosan [47].

However, taking into account the obtained results, it has to be noted that the addition of $3 \mathrm{wt} . \%$ of a crosslinking agent causes a significant increase in thermal stability of the obtained material. This suggests that squaric acid in higher concentrations is able to enhance intermolecular interaction and simultaneously stimulate hydrogen bond formation. Therefore, it is justified to assume that this leads to the formation of a more compact molecular structure of the polysaccharide carbon chains which are less susceptible to decomposition [48]. To summarize, the analysis of the thermal properties and stability indicates that a high amount of squaric acid can significantly affect the thermal stability of chitosan-based materials.

\subsection{Mechanical Properties}

To establish the influence of squaric acid on the properties of chitosan-based films, the mechanical resistance was tested. Mechanical parameters such as Young's modulus $\left(E_{\text {mod }}\right)$, tensile strength $(\sigma)$ and percentage elongation at break $(\varepsilon)$ in relation to chitosan and chitosan with 1, 2 and $3 \mathrm{wt} . \%$ squaric acid addition, have been determined and compared. The results of Young's modulus, tensile strength, and percentage elongation are shown in Figure 9.
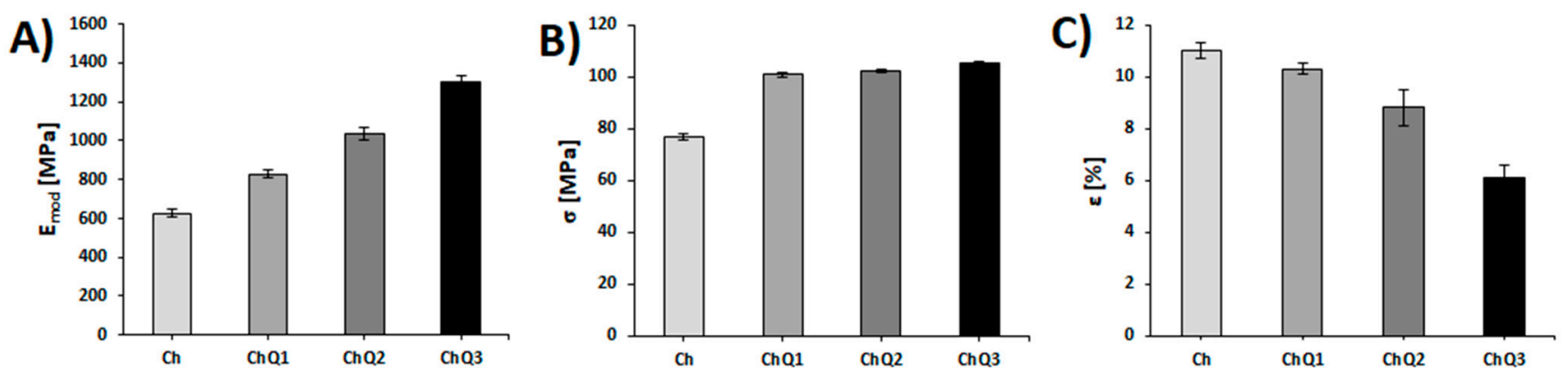

Figure 9. (A) Young's modulus $\left(\mathrm{E}_{\mathrm{mod}}\right)$; (B) tensile strength $(\sigma)$, and $(\mathbf{C})$ percentage elongation $(\varepsilon)$ of chitosan and chitosan with squaric acid 1,2 , and 3 wt. $\%$ addition. 
The addition of squaric acid increases the Young's modulus' values, which is indicative of the elasticity and rigidity of the sample [49]. It should be stressed that the increase in the values of the Young's modulus, in comparison to pure chitosan, is observed in the case of all of the obtained materials with an addition of squaric acid. Moreover, it can be seen that a film made of chitosan with a $3 \mathrm{wt}$.\% addition of squaric acid is characterized by the highest values of the Young's modulus. The introduction of a crosslinking agent into chitosan causes the films to become less flexible and more rigid than a pure chitosan film. An analogous correlation has been noted in the case of collagen/elastin blends crosslinked by squaric acid [20]. The value of $E_{\text {mod }}$ calculated for the ChQ3 sample (1302 $\left.\pm 34 \mathrm{MPa}\right)$ is more than twice as high as the value recorded in relation to chitosan before modification $(625 \pm 21 \mathrm{MPa})$. In the work of Skopińska-Wiśniewska [20], the same tendency has been described: a high-compression modulus in relation to all of the crosslinked collagen-elastin based samples.

The obtained results lead also to the conclusion that films with an addition of squaric acid exhibit higher values of tensile strength $(\sigma)$ than films made of chitosan without crosslinking (Figure 9B). This clearly indicates that the force which was applied to break the crosslinked films was greater than the force required to break the samples without the crosslinker. After the crosslinking process, the tensile strength increases. The greatest tensile strength value was observed in the case of chitosan with $3 \mathrm{wt}$.\% addition of squaric acid. Wegrzynowska-Drzymalska et al. studied chitosan films crosslinked with dialdehyde starch (5 and $10 \mathrm{wt} . \%)$, dialdehyde chitosan (5, 10, and $15 \mathrm{wt. \%})$, and glutaraldehyde [50], and also noted that tensile strength increased with an increased amount of the crosslinker in the chitosan films. They reported that the most significant differences in tensile strength values were observed in relation to chitosan crosslinked with dialdehyde chitosan. Similar observations were made by Tang et al. [51] in the case of dialdehyde starch-crosslinked chitosan films. The authors reported that the tensile strength of all of the crosslinked films $(1,3,5,7$, and 9 wt.\% of crosslinker) were higher than that of the pure chitosan film and increased with the increase in the dialdehyde starch content.

The studied materials are characterized by the value of percentage elongation at break $(\varepsilon)$ inversely proportional to the value of the Young's modulus (Figure 9C). When the Young's modulus' value is higher, the percentage elongation value is lower, with the sample being more rigid and less elastic. This phenomenon can be attributed to the reduced mobility of polymeric chains related to the crosslinking process. The addition of $\mathrm{H}_{2} \mathrm{SQ}$ results in the disruption of the existing hydrogen bonds in chitosan, while new strong covalent crosslinks are formed at the same time. A similar effect of crosslinking on material elasticity was observed by Frick et al. [52]. Wegrzynowska-Drzymalska et al. [50] indicated that the elongation at break of chitosan-based materials decreases when a higher amount of crosslinking agent (glutaraldehyde) is used. Pavoni et al. [53] also investigated the effect that addition of glutaraldehyde $(0.5,1,2,5$, and $10 \mathrm{wt}$ \% glutaraldehyde content) had on the mechanical properties of chitosan. They observed that the application of the crosslinking agent promoted a decrease in the elongation at break, from $45 \pm 3 \%$ (pure chitosan) to $3 \pm 1 \%$ in the case of chitosan crosslinked with $10 \mathrm{wt} \% \%$ of glutaraldehyde. All of the findings discussed above are consistent with those presented in Figure 9 relating to $\mathrm{H}_{2} \mathrm{SQ}$-crosslinked chitosan.

These observations lead to the conclusion that increasing the dose of a crosslinking agent is effective in inducing significant changes to the mechanical properties of the films. The addition of squaric acid to chitosan has an effect on all of the mechanical parameters of the films measured in this study. This suggests that during the addition of squaric acid to chitosan, crosslinking reactions in the film occur and are responsible for an improvement in mechanical properties. All of the above discussed changes in $\mathrm{E}_{\mathrm{mod}}, \sigma$, and $\varepsilon$ parameters stay also in agreement with the results of FTIR analysis: a higher content of crosslinking agent in chitosan-based films results in a higher number of covalent crosslinks, thus a more rigid polymeric matrix is formed. 
Various crosslinking agents have been tested recently, e.g., glutaraldehyde, formaldehyde, dialdehyde starch, tannic acid, and others [51,54-56]. Many of these compounds can effectively be used in crosslinking polymers. Researchers, however, are constantly looking for new crosslinking agents to improve the properties of polymers. Squaric acid, due to the presence of functional groups, is very reactive and therefore the mechanical properties of the modified materials are superior to the ones displayed by pure chitosan [57].

\subsection{Differences in Color of Chitosan-Based Materials}

It is well known that color psychology plays an important role, especially in advertising and retail sales. A significant number of consumers decide to buy a particular product only based on the product's color, particularly when the products are homogeneous. For this reason, color is often taken into account by material designers and psychologists. Bearing in mind how important coloristics are, different methods are used to establish the most appropriate shade and color of materials. One of the popular techniques is the CIE Lab system. This method was also applied in the case of other materials, which were the object of our previous studies [58]. Based on the values of the measured parameters L, a, and $\mathrm{b}$, the $\Delta \mathrm{E}$ parameter was calculated (Table 3 ).

Table 3. Color variables of studied materials.

\begin{tabular}{ccccc}
\hline \multirow{2}{*}{ Sample } & \multicolumn{4}{c}{ Color Variable $^{\mathbf{1}}$} \\
\cline { 2 - 5 } & $\mathbf{L}$ & $\mathbf{a}$ & $\mathbf{b}$ & $\boldsymbol{\Delta} \mathbf{E}$ \\
\hline Ch & $90.40 \pm 0.23$ & $-1.40 \pm 0.02$ & $5.04 \pm 0.02$ & - \\
ChQ1 & $82.51 \pm 0.13$ & $-3.21 \pm 0.06$ & $24.39 \pm 0.09$ & $21.0 \pm 0.19$ \\
ChQ2 & $79.94 \pm 0.09$ & $-3.93 \pm 0.06$ & $27.63 \pm 0.11$ & $25.0 \pm 0.21$ \\
ChQ3 & $77.42 \pm 0.21$ & $-4.23 \pm 0.09$ & $29.51 \pm 0.07$ & $27.9 \pm 0.13$ \\
\hline
\end{tabular}

${ }^{1}$ mean value (three replicates).

The obtained results clearly indicate that the amount of squaric acid used as a crosslinking agent significantly influences the final color of the obtained materials in comparison with unmodified chitosan. Based on the results presented in Table 3 it is apparent that the $\Delta \mathrm{E}$ values of $\mathrm{ChQ}$ films exceeds 20 . Taking into account that significant changes in color can be noticed by a consumer when the value of $\Delta \mathrm{E}$ exceeds 5 , the obtained results lead to the conclusion that the application of squaric acid will be clearly visible to potential consumers. The tests reveal that the most significant changes were observed in the case of the $\mathrm{L}$ and $\mathrm{b}$ parameters. The increase in $\mathrm{b}$ parameter indicates that the color of materials is a more intense yellow in comparison with pure chitosan, while a decrease in the L parameter value suggests that chitosan crosslinked using squaric acid tends to be darker when compared to the original sample.

\section{Materials and Methods}

\subsection{Materials}

The commercially available chitosan from crab shells of $72.25 \pm 0.77 \%$ degree of deacetylation was supplied by BioLog Heppe GmbH (Landsberg, Germany). Squaric acid $\left(\mathrm{H}_{2} \mathrm{SQ}\right.$, Sigma-Aldrich, Germany) was applied as the crosslinking agent. Acetic acid was purchased from Avantor Performance Materials Poland S.A. (Gliwice, Poland). To perform the analysis of swelling the following buffer solutions of constant ionic strength were prepared: acetic buffer $(\mathrm{pH}=4.5)$ and Tris buffers $(\mathrm{pH}=7.4 ; 8.5 ; 9.0)$. The reagents purchased at Avantor Performance Materials Poland S.A. (Gliwice, Poland) used for the preparation of the buffer solutions mentioned above were as follows: hydrochloric acid 35-38\%, sodium acetate, sodium chloride, Tris(hydroxsymetyl) aminometane, and sodium chloride.

\subsection{Formation of Chitosan-Based Films}

In order to obtain uncrosslinked and crosslinked chitosan-based films, the casting and the solvent evaporation techniques were used. In the first stage, the $1 \mathrm{wt} . \%$ chitosan 
(Ch) solution was prepared by dissolving chitosan in $2 \%(w / v)$ acetic acid. In the second stage, squaric acid, dissolved in a small amount of distilled water, was introduced into the chitosan solution. The squaric acid weight equaled 1, 2, or $3 \mathrm{wt} . \%$ of the chitosan mass. All of the obtained solutions were cast on polystyrene plates and dried for $48 \mathrm{~h}$ at $37^{\circ} \mathrm{C}$. Subsequently, plates were placed in vacuum for $24 \mathrm{~h}$ at the same temperature. It needs to be noted that the ratio between the solution volume and the polystyrene plate surface was adjusted to eventually achieve a $0.1 \mathrm{~mm}$ film thickness. The obtained pure chitosan and chitosan-based films containing 1,2, and 3 wt.\% of the crosslinking agent were described as: $\mathrm{Ch}, \mathrm{ChQ1}, \mathrm{ChQ} 2$, and ChQ3 respectively.

\subsection{Methods of Analysis}

\subsubsection{Fourier Transform Infrared Spectroscopy (FTIR)}

The Fourier transform infrared-Attenuated Total Reflectance (FTIR-ATR) spectra, obtained using zinc selenide crystal, of $\mathrm{Ch}$ and $\mathrm{ChQ}$ films were registered within the frequency range of $500-4000 \mathrm{~cm}^{-1}$. The FTIR spectra of squaric acid $\left(\mathrm{H}_{2} \mathrm{SQ}\right)$ were recorded in $\mathrm{KBr}$ disc form using a device working in transmittance mode. Final spectra are a result of 64 scans at the spectral resolution of $2 \mathrm{~cm}^{-1}$. In each of the (FTIR and FTIR-ATR) analyses Nicolet iS10 (Thermo Fisher Scientific, Waltham, USA) was applied. OMNIC 7.0 software (Thermo Fisher Scientific, Waltham, USA) was also employed for spectra analysis.

\subsubsection{Atomic Force Microscopy (AFM)}

The topographic images were obtained using a multimode scanning probe microscope with a NanoScope IIIa controller (Digital Instruments, Santa Barbara, CA, USA) operating in the tapping mode, in air, at room temperature. Surface images were acquired at a fixed resolution ( $512 \times 512$ data points) using a scan width of $5 \mu \mathrm{m}$ with a scan rate of $1.97 \mathrm{~Hz}$. Three replicates were performed in the case of each film. Silicon tips with a spring constant of $2-10 \mathrm{~N} / \mathrm{m}$ were used. Parameters such as the root mean square roughness $\left(\mathrm{R}_{\mathrm{q}}\right)$ and roughness average $\left(R_{a}\right)$ were calculated from $25 \mu \mathrm{m}^{2}$ surface area using NanoScope Analysis software.

\subsubsection{Thermogravimetric Analysis (TG)}

Simultaneous TGA-DTA Thermal Analysis type SDT 2960 (TA Instruments, New Castle, DE, USA) equipment was applied in order to determine the thermal stability of the obtained materials. All measurements were performed under air flow from room temperature to $600{ }^{\circ} \mathrm{C}$ at a heating rate of $10^{\circ} \mathrm{C} / \mathrm{min}$. Two replicates were performed in the case of each film.

\subsubsection{Mechanical Properties}

The mechanical properties of the materials were measured using a mechanical testing machine: TIRAtest 27025. Young's modulus, tensile strength, and percentage elongation of polymer films based on chitosan with an addition of squaric acid were measured at room temperature in the dry state and at a crosshead speed of $50 \mathrm{~mm} / \mathrm{min}$ in accordance with the procedure outlined in the PN-EN ISO 527-1-3 standard. Samples were cut into paddleshaped pieces, with initial dimensions that constituted $25 \mathrm{~mm}$ in length $\left(\mathrm{L}_{0}\right), 5 \mathrm{~mm}$ in width $\left(b_{1}\right)$, and $1 \mathrm{~mm}$ thickness (h) (Figure 10). The thickness of the samples was measured by a type A-91 ultrameter (producer: Manufacture of Electronic Devices, Warsaw, Poland). All of the film samples were cut using the same shaper. In the case of each type of film, at least five samples were tested. 


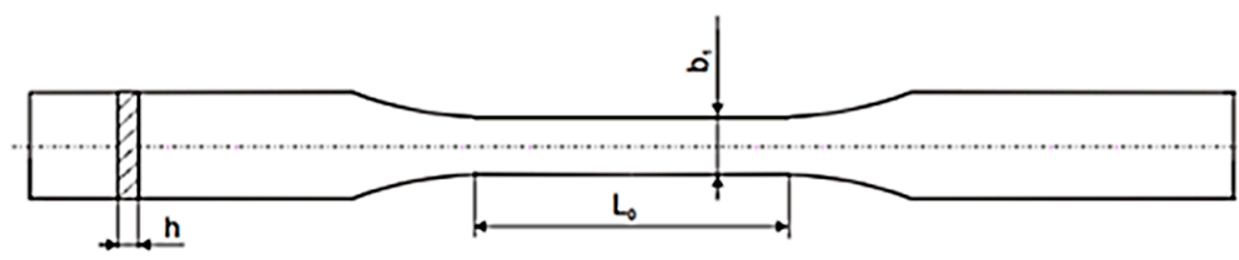

Figure 10. Shape of samples with dimension markings.

\subsubsection{Color Measurement}

The color of chitosan films undergoing squaric acid crosslinking was determined using a MICRO-COLOR II LCM 6 (Dr Lange) colorimeter. Based on the CIE Lab system the color difference $(\Delta \mathrm{E})$ of materials was calculated. In order to establish the total values of $\Delta \mathrm{E}$ the Equation (3) presented below was applied.

$$
\Delta \mathrm{E}=\sqrt{\left(\mathrm{L}-\mathrm{L}^{*}\right)^{2}+\left(\mathrm{a}-\mathrm{a}^{*}\right)^{2}+\left(\mathrm{b}-\mathrm{b}^{*}\right)^{2}},
$$

Particular characteristics were described using the following parameters: L-lightness, $\mathrm{a}-$ colors ranging from green $(-\mathrm{a})$ to red $(+a)$, and $\mathrm{b}-$ colors ranging from blue $(-\mathrm{b})$ to yellow $(+b)$. The color of the studied materials was expressed as L (lightness), a (redness/greenness), and $b$ (yellowness/blueness) values [58]. Chitosan film without an addition of squaric acid was used as a reference sample ( $\mathrm{L}^{*}, \mathrm{a}^{*}$, and $\mathrm{b}^{*}$ values). Three replicates were performed in the case of each film.

\subsubsection{Swelling}

The swelling behavior of pristine chitosan and squaric acid-crosslinked chitosan films was evaluated with the gravimetric method. Dry polymeric film of $1 \mathrm{~cm} \times 1 \mathrm{~cm}$ was weighed $\left(W_{0}\right.$, ca. $\left.20 \mathrm{mg}\right)$, placed in $100 \mathrm{~cm}^{3}$ of swelling media $\left(\mathrm{T}=37.0 \pm 0.1^{\circ} \mathrm{C}\right)$, and kept for $24 \mathrm{~h}$ under gentle stirring. The $24 \mathrm{~h}$ swelling time was determined, through the swelling kinetic measurements, to be sufficient to reach an equilibrium swelling state by all tested films. The swollen film was removed from the solution and weighed $\left(W_{e q}\right)$ after an excess of solvent was eliminated with filter paper. The equilibrium degree of swelling $\left(S_{e q}\right.$ $\left.\left[\mathrm{g}_{\text {water }} \cdot \mathrm{g}_{\text {polymer }}{ }^{-1}\right]\right)$ was calculated as:

$$
S_{e q}=\frac{W_{e q}-W_{0}}{W_{0}} .
$$

To avoid an effect of pretreatment on the swelling of the polymeric film, samples of similar thickness and surface, dried in analogous conditions, were used. Final $S_{e q}$ values constitute a mean from three independent measurements. In each case relative standard deviations were lower than $5 \%$.

In all swelling experiments distilled water and the following buffered solutions of constant ionic strength $(0.145 \mathrm{M})$ were used: $10 \mathrm{mM}$ acetic acid/sodium acetate solutions (acetate buffer, $\mathrm{pH} 4.5$ ) and $10 \mathrm{mM}$ Tris buffered solutions (pH 7.4, 8.5, and 9.0).

\subsubsection{Theoretical Degree of Chitosan Crosslinking}

The theoretical degree of crosslinking [\%] was calculated by the amino content of chitosan after $\mathrm{H}_{2} \mathrm{SQ}$ addition and the amino content of raw chitosan:

$$
\text { Degree of crosslinking }=\frac{I_{N H 2}-F_{N H 2}}{I_{N H 2}} \cdot 100 \%,
$$

where $I_{\mathrm{NH} 2}$ and $F_{\mathrm{NH} 2}$ are the initial and final moles of $\mathrm{NH}_{2}$ functional groups in chitosan samples, respectively. The difference $I_{\mathrm{NH} 2}-F_{\mathrm{NH} 2}$ represents the moles of $\mathrm{NH}_{2}$ groups 
involved in the formation of the crosslinks, assuming that one mole of the crosslinker reacts with two moles of the $-\mathrm{NH}_{2}$ functional groups, and can be calculated as:

$$
I_{N H 2}-F_{N H 2}=2 \cdot \frac{m}{M}
$$

where $M$ is the molar mass of squaric acid, $114.06 \mathrm{~g} \cdot \mathrm{mol}^{-1}$, and $m$ represents the $\mathrm{H}_{2} \mathrm{SQ}$ mass per known amount of crosslinked chitosan, equal to $0.01,0.02$, and $0.03 \mathrm{~g}$ per $1 \mathrm{~g}$ of chitosan, for ChQ1, ChQ2, and ChQ3 samples, respectively.

\section{Conclusions}

Novel crosslinked materials based on chitosan and squaric acid were successfully formed. Their structure and morphology were established by means of FTIR and AFM techniques. The analysis of the FTIR spectra confirmed that the covalently crosslinked chitosan films were obtained. The other fact which must be noted is that the addition of squaric acid did not significantly influence the roughness of the obtained chitosan-based films. Because of the apparent compatibility, the surface of the crosslinked materials was smooth.

The introduction of squaric acid into chitosan significantly improved Young's modulus and tensile strength. The same tendency was observed in the case of the thermal stability of the crosslinked materials. These changes are a direct result of the crosslinks formed between chitosan and squaric acid. Evaluation of the color changes showed that squaric acid can play an important role in the perception of the obtained materials by prospective consumers.

Simultaneously, it was also proved that all films being in contact with different external media differ in swelling capacity as a result of different $\mathrm{pH}$ levels affecting the ionization of functional groups, crosslinking density, and hydrophobic/hydrophilic balance. All films were stable in a solution of $\mathrm{pH}$ higher than 7.4. Moreover, crosslinked chitosan samples did not dissolve in water and as little as $1 \mathrm{wt} . \%$ of the crosslinker ensured the stability of the chitosan films in this media.

In conclusion, based on the performed analyses, it was established that squaric acid is an efficient crosslinker that can effectively replace currently used, toxic crosslinkers like glutaraldehyde.

Author Contributions: Conceptualization, E.O.-K., M.G. and J.S.-W.; methodology, E.O.-K. and M.G.; software, E.O.-K., M.G., S.G.-Z. and E.J.; validation, E.O.-K., M.G. and S.G.-Z.; formal analysis, E.O.-K., M.G. and E.J.; investigation, E.O.-K. and M.G.; writing—original draft preparation E.O.-K., M.G. and S.G.-Z.; writing-review and editing, E.O.-K., M.G. and S.G.-Z.; visualization, E.O.-K., M.G. and S.G.-Z.; supervision, E.O.-K. and M.G. All authors have read and agreed to the published version of the manuscript.

Funding: This research was funded by Nicolaus Copernicus University in Torun ("Excellence Initiative-Research University—Debuts" programme, 1st edition).

Institutional Review Board Statement: Not applicable.

Informed Consent Statement: Not applicable.

Data Availability Statement: The data presented in this study are available on request from the corresponding author.

Conflicts of Interest: The authors declare no conflict of interest. The funders had no role in the design of the study; in the collection, analyses, or interpretation of data; in the writing of the manuscript; or in the decision to publish the results. 


\section{References}

1. Anitha, A.; Rejinold, N.S.; Bumgardner, J.D.; Nair, S.V.; Jayakumar, R. Approaches for Functional Modification or Cross-Linking of Chitosan. In Chitosan-Based Systems for Biopharmaceuticals; John Wiley \& Sons, Ltd.: Chichester, UK, 2012; Volume 95, pp. 107-124. ISBN 9780470978320.

2. Ostrowska-Czubenko, J.; Pieróg, M.; Gierszewska-Drużyńska, M. Water state in chemically and physically crosslinked chitosan membranes. J. Appl. Polym. Sci. 2013, 130, 1707-1715. [CrossRef]

3. Gierszewska, M.; Jakubowska, E.; Olewnik-Kruszkowska, E. Effect of chemical crosslinking on properties of chitosanmontmorillonite composites. Polym. Test. 2019, 77, 105872. [CrossRef]

4. Li, H.; Gao, X.; Wang, Y.; Zhang, X.; Tong, Z. Comparison of chitosan/starch composite film properties before and after cross-linking. Int. J. Biol. Macromol. 2013, 52, 275-279. [CrossRef] [PubMed]

5. Nagireddi, S.; Katiyar, V.; Uppaluri, R. Pd(II) adsorption characteristics of glutaraldehyde cross-linked chitosan copolymer resin. Int. J. Biol. Macromol. 2017, 94, 72-84. [CrossRef] [PubMed]

6. Bera, B.; Das, J.K.; Das, N. Mesoporous silica based composite membrane formation by in-situ cross-linking of phenol and formaldehyde at room temperature for enhanced CO 2 separation. Microporous Mesoporous Mater. 2018, 256, 177-189. [CrossRef]

7. Sun, S.; Liu, P.; Ji, N.; Hou, H.; Dong, H. Effects of various cross-linking agents on the physicochemical properties of starch/PHA composite films produced by extrusion blowing. Food Hydrocoll. 2018, 77, 964-975. [CrossRef]

8. Cittan, M.; Tirtom, V.N.; Dinçer, A.; Çelik, A. Epichlorohydrin crosslinked chitosan-clay composite beads for on-line preconcentration and determination of chromium(iii) by flow injection flame atomic absorption spectrometry. Anal. Methods 2014, 6, 5298. [CrossRef]

9. Aqil, A.; Tchemtchoua, V.T.; Colige, A.; Atanasova, G.; Poumay, Y.; Jérôme, C. Preparation and characterizations of EGDE crosslinked chitosan electrospun membranes. Clin. Hemorheol. Microcirc. 2015, 60, 39-50. [CrossRef]

10. Kimura, S.; Isobe, N.; Wada, M.; Kuga, S.; Ko, J.-H.; Kim, U.-J. Enzymatic hydrolysis of chitosan-dialdehyde cellulose hydrogels. Carbohydr. Polym. 2011, 83, 1850-1853. [CrossRef]

11. Paradossi, G.; Chiessi, E.; Cavalieri, F.; Moscone, D.; Crescenzi, V. Networks based on chitosan and oxidized cyclodextrin-II. Structural and catalytic features of a copper (II)-loaded network. Polym. Gels Netw. 1998, 5, 525-540. [CrossRef]

12. He, X.; Du, M.; Li, H.; Zhou, T. Removal of direct dyes from aqueous solution by oxidized starch cross-linked chitosan/silica hybrid membrane. Int. J. Biol. Macromol. 2016, 82, 174-181. [CrossRef]

13. Grabska-Zielińska, S.; Sionkowska, A.; Reczyńska, K.; Pamuła, E. Physico-Chemical Characterization and Biological Tests of Collagen/Silk Fibroin/Chitosan Scaffolds Cross-Linked by Dialdehyde Starch. Polymers 2020, 12, 372. [CrossRef]

14. Liu, G.; Shi, Z.; Kuriger, T.; Hanton, L.R.; Simpson, J.; Moratti, S.C.; Robinson, B.H.; Athanasiadis, T.; Valentine, R.; Wormald, P.J.; et al. Synthesis and Characterization of Chitosan/Dextran-Based Hydrogels for Surgical Use. Macromol. Symp. 2009, 279, 151-157. [CrossRef]

15. Perez-Puyana, V.; Jiménez-Rosado, M.; Romero, A.; Guerrero, A. Crosslinking of hybrid scaffolds produced from collagen and chitosan. Int. J. Biol. Macromol. 2019, 139, 262-269. [CrossRef]

16. O'Brien, F.; Harley, B.A.; Yannas, I.V.; Gibson, L. Influence of freezing rate on pore structure in freeze-dried collagen-GAG scaffolds. Biomaterials 2004, 25, 1077-1086. [CrossRef]

17. Moreira Teixeira, L.S.; Feijen, J.; van Blitterswijk, C.A.; Dijkstra, P.J.; Karperien, M. Enzyme-catalyzed crosslinkable hydrogels: Emerging strategies for tissue engineering. Biomaterials 2012, 33, 1281-1290. [CrossRef] [PubMed]

18. Wurm, F.R.; Klok, H.-A. Be squared: Expanding the horizon of squaric acid-mediated conjugations. Chem. Soc. Rev. 2013, $42,8220$. [CrossRef] [PubMed]

19. Ziegler-Borowska, M.; Mylkie, K.; Nowak, P.; Rybczynski, P.; Sikora, A.; Chelminiak-Dudkiewicz, D.; Kaczmarek-Kedziera, A. Testing for Ketoprofen Binding to HSA Coated Magnetic Nanoparticles under Normal Conditions and after Oxidative Stress. Molecules 2020, 25, 1945. [CrossRef] [PubMed]

20. Skopinska-Wisniewska, J.; Kuderko, J.; Bajek, A.; Maj, M.; Sionkowska, A.; Ziegler-Borowska, M. Collagen/elastin hydrogels cross-linked by squaric acid. Mater. Sci. Eng. C 2016, 60, 100-108. [CrossRef]

21. Pearson, F.G.; Marchessault, R.H.; Liang, C.Y. Infrared spectra of crystalline polysaccharides. V. Chitin. J. Polym. Sci. 1960, $43,101-116$. [CrossRef]

22. Ostrowska-Czubenko, J.; Gierszewska-Drużyńska, M. Effect of ionic crosslinking on the water state in hydrogel chitosan membranes. Carbohydr. Polym. 2009, 77, 590-598. [CrossRef]

23. Pawlak, A.; Mucha, M. Thermogravimetric and FTIR studies of chitosan blends. Thermochim. Acta 2003, 396, 153-166. [CrossRef]

24. Smitha, B.; Sridhar, S.; Khan, A.A. Chitosan-sodium alginate polyion complexes as fuel cell membranes. Eur. Polym. J. 2005, 41, 1859-1866. [CrossRef]

25. Baglin, F.G.; Rose, C.B. The infrared and Raman spectra of crystalline squaric acid. Spectrochim. Acta 1970, 26 A, $2293-2304$. [CrossRef]

26. Georgopoulos, S.L.; Diniz, R.; Yoshida, M.I.; Speziali, N.L.; Dos Santos, H.F.; Junqueira, G.M.A.; de Oliveira, L.F.C. Vibrational spectroscopy and aromaticity investigation of squarate salts: A theoretical and experimental approach. J. Mol. Struct. 2006, 794, 63-70. [CrossRef]

27. Rao, C.N.R. Chemical Application of Infrared Spectroscopy; Academic Press: New York, NY, USA, 1963. 
28. Ostrowska-Czubenko, J.; Gierszewska, M.; Pieróg, M. pH-responsive hydrogel membranes based on modified chitosan: Water transport and kinetics of swelling. J. Polym. Res. 2015, 22, 153. [CrossRef]

29. Knaul, J.Z.; Hudson, S.M.; Creber, K.A.M. Improved mechanical properties of chitosan fibers. J. Appl. Polym. Sci. 1999, 72, 1721-1732. [CrossRef]

30. Ziegler-Borowska, M.; Chelminiak-Dudkiewicz, D.; Siódmiak, T.; Sikora, A.; Wegrzynowska-Drzymalska, K.; SkopinskaWisniewska, J.; Kaczmarek, H.; Marszałł, M. Chitosan-Collagen Coated Magnetic Nanoparticles for Lipase Immobilization-New Type of "Enzyme Friendly" Polymer Shell Crosslinking with Squaric Acid. Catalysts 2017, 7, 26. [CrossRef]

31. Souza, N.L.G.D.; Salles, T.F.; Brandão, H.M.; Edwards, H.G.M.; de Oliveira, L.F.C. Synthesis, Vibrational Spectroscopic and Thermal Properties of Oxocarbon Cross-Linked Chitosan. J. Br. Chem. Soc. 2015, 26, 1247-1256. [CrossRef]

32. Flory, P.J.; Rehner, J. Statistical Mechanics of Cross-Linked Polymer Networks II. Swelling. J. Chem. Phys. 1943, 11, 521-526. [CrossRef]

33. Peppas, N. Hydrogels in pharmaceutical formulations. Eur. J. Pharm. Biopharm. 2000, 50, 27-46. [CrossRef]

34. Siegel, R.A.; Johannes, I.; Hunt, C.A.; Firestone, B.A. Buffer Effects on Swelling Kinetics in Polybasic Gels. Pharm. Res. An Off. J. Am. Assoc. Pharm. Sci. 1992, 9, 76-81.

35. Berger, J.; Reist, M.; Mayer, J.M.; Felt, O.; Peppas, N.A.; Gurny, R. Structure and interactions in covalently and ionically crosslinked chitosan hydrogels for biomedical applications. Eur. J. Pharm. Biopharm. 2004, 57, 19-34. [CrossRef]

36. Domard, A. pH and c.d. measurements on a fully deacetylated chitosan: Application to CuII-polymer interactions. Int. J. Biol. Macromol. 1987, 9, 98-104. [CrossRef]

37. Mi, F.-L.; Shyu, S.-S.; Wong, T.-B.; Jang, S.-F.; Lee, S.-T.; Lu, K.-T. Chitosan-polyelectrolyte complexation for the preparation of gel beads and controlled release of anticancer drug. II. Effect of $\mathrm{pH}$-dependent ionic crosslinking or interpolymer complex using tripolyphosphate or polyphosphate as reagent. J. Appl. Polym. Sci. 1999, 74, 1093-1107. [CrossRef]

38. Mi, F.-L.; Shyu, S.-S.; Lee, S.-T.; Wong, T.-B. Kinetic study of chitosan-tripolyphosphate complex reaction and acid-resistive properties of the chitosan-tripolyphosphate gel beads prepared by in-liquid curing method. J. Polym. Sci. Part B Polym. Phys. 1999, 37, 1551-1564. [CrossRef]

39. Peppas, N.A.; Khare, A.R. Preparation, structure and diffusional behavior of hydrogels in controlled release. Adv. Drug Deliv. Rev. 1993, 11, 1-35. [CrossRef]

40. Shikata, T.; Okuzono, M. Are All Polar Molecules Hydrophilic? Hydration Numbers of Ketones and Esters in Aqueous Solution. J. Phys. Chem. B 2013, 117, 7718-7723. [CrossRef]

41. Ewing, A.V.; Gabrienko, A.A.; Semikolenov, S.V.; Dubkov, K.A.; Kazarian, S.G. How Do Intermolecular Interactions Affect Swelling of Polyketones with a Differing Number of Carbonyl Groups? An In Situ ATR-FTIR Spectroscopic Study of $\mathrm{CO}_{2}$ Sorption in Polymers. J. Phys. Chem. C 2015, 119, 431-440. [CrossRef]

42. Gadelmawla, E.S.; Koura, M.M.; Maksoud, T.M.A.; Elewa, I.M.; Soliman, H.H. Roughness parameters. J. Mater. Process. Technol. 2002, 123, 133-145. [CrossRef]

43. Yap, W.F.; Yunus, W.M.M.; Talib, Z.A.; Yusof, N.A. X-ray photoelectron spectroscopy and atomic force microscopy studies on crosslinked chitosan thin film. Int. J. Phys. Sci. 2011, 6, 2744-2749. [CrossRef]

44. Sionkowska, A.; Michalska-Sionkowska, M.; Walczak, M. Preparation and characterization of collagen/hyaluronic acid/chitosan film crosslinked with dialdehyde starch. Int. J. Biol. Macromol. 2020, 149, 290-295. [CrossRef]

45. Sionkowska, A.; Kaczmarek, B.; Gnatowska, M.; Kowalonek, J. The influence of UV-irradiation on chitosan modified by the tannic acid addition. J. Photochem. Photobiol. B Biol. 2015, 148, 333-339. [CrossRef]

46. Lewandowska, K. Miscibility and thermal stability of poly(vinyl alcohol)/chitosan mixtures. Thermochim. Acta 2009, 493, 42-48. [CrossRef]

47. Lewandowska, K.; Sionkowska, A.; Kaczmarek, B.; Furtos, G. Characterization of chitosan composites with various clays. Int. J. Biol. Macromol. 2014, 65, 534-541. [CrossRef]

48. Li, K.; Zhu, J.; Guan, G.; Wu, H. Preparation of chitosan-sodium alginate films through layer-by-layer assembly and ferulic acid crosslinking: Film properties, characterization, and formation mechanism. Int. J. Biol. Macromol. 2019, 122, 485-492. [CrossRef] [PubMed]

49. Grabska, S.; Sionkowska, A. Preparation and characterization of biopolymeric films with magnetic properties. Mol. Cryst. Liq. Cryst. 2018, 670, 80-89. [CrossRef]

50. Wegrzynowska-Drzymalska, K.; Grebicka, P.; Mlynarczyk, D.T.; Chelminiak-Dudkiewicz, D.; Kaczmarek, H.; Goslinski, T.; Ziegler-Borowska, M. Crosslinking of Chitosan with Dialdehyde Chitosan as a New Approach for Biomedical Applications. Materials 2020, 13, 3413. [CrossRef] [PubMed]

51. Tang, R.; Du, Y.; Fan, L. Dialdehyde starch-crosslinked chitosan films and their antimicrobial effects. J. Polym. Sci. Part B Polym. Phys. 2003, 41, 993-997. [CrossRef]

52. Frick, J.M.; Ambrosi, A.; Pollo, L.D.; Tessaro, I.C. Influence of Glutaraldehyde Crosslinking and Alkaline Post-treatment on the Properties of Chitosan-Based Films. J. Polym. Environ. 2018, 26, 2748-2757. [CrossRef]

53. Pavoni, J.M.F.; dos Santos, N.Z.; May, I.C.; Pollo, L.D.; Tessaro, I.C. Impact of acid type and glutaraldehyde crosslinking in the physicochemical and mechanical properties and biodegradability of chitosan films. Polym. Bull. 2021, 78, 981-1000. [CrossRef]

54. Marquie, C.; Aymard, C.; Cuq, J.L.; Guilbert, S. Biodegradable Packaging Made from Cottonseed Flour: Formation and Improvement by Chemical Treatments with Gossypol, Formaldehyde, and Glutaraldehyde. J. Agric. Food Chem. 1995, 43, 2762-2767. [CrossRef] 
55. Halim, A.L.A.; Kamari, A.; Phillip, E. Chitosan, gelatin and methylcellulose films incorporated with tannic acid for food packaging. Int. J. Biol. Macromol. 2018, 120, 1119-1126. [CrossRef]

56. Suganthi, S.; Vignesh, S.; Kalyana Sundar, J.; Raj, V. Fabrication of PVA polymer films with improved antibacterial activity by fine-tuning via organic acids for food packaging applications. Appl. Water Sci. 2020, 10, 100. [CrossRef]

57. Onaran, M.B.; Comeau, A.B.; Seto, C.T. Squaric Acid-Based Peptidic Inhibitors of Matrix Metalloprotease-1. J. Org. Chem. 2005, 70, 10792-10802. [CrossRef]

58. Olewnik-Kruszkowska, E.; Gierszewska, M.; Jakubowska, E.; Tarach, I.; Sedlarik, V.; Pummerova, M. Antibacterial Films Based on PVA and PVA-Chitosan Modified with Poly(Hexamethylene Guanidine). Polymers 2019, 11, 2093. [CrossRef] [PubMed] 